\title{
Is two-dimensional echocardiography better than electrocardiography for predicting patient outcomes after cardiac arrest?
}

\author{
Dong Ki Kim, Yong Soo Cho, Joochan Kim, Byung Kook Lee, Dong Hun Lee, Eujene Jung, Jeong Mi Moon, \\ Byeong Jo Chun
}

Department of Emergency Medicine, Chonnam National University Hospital, Gwangju, Korea

Background: Coronary artery stenosis increases hospital mortality and leads to poor neurological recovery in cardiac arrest (CA) patients. However, electrocardiography (ECG) cannot fully predict the presence of coronary artery stenosis in CA patients. Hence, we aimed to determine whether regional wall motion abnormality (RWMA), as observed by two-dimensional echocardiography (2DE), predicted patient survival outcomes with greater accuracy than did ST segment elevation (STE) on ECG in CA patients who underwent coronary angiography (CAG) after return of spontaneous circulation.

Methods: This was a retrospective observational study of adult patients with CA of presumed cardiac etiology who underwent CAG at a single tertiary care hospital. We investigated whether RWMA observed on 2DE predicted patient outcomes more accurately than did STE observed on ECG. The primary outcome was incidence of hospital mortality. The secondary outcomes were Glasgow-Pittsburgh Cerebral Performance Category scores measured 6 months after discharge and significant coronary artery stenosis on CAG.

Results: Among the 145 patients, 36 (24.8\%) experienced in-hospital death. In multivariable analysis of survival outcomes, only total arrest time $(P=0.011)$ and STE $(P=0.035)$ were significant. The odds ratio $(\mathrm{OR})$ and $95 \%$ confidence interval $(\mathrm{CI})$, which were obtained by adjusting the total arrest time for survival outcomes, were significant only for STE (OR, 0.40; $95 \% \mathrm{Cl}, 0.17-0.94)$. The presence of RWMA was not a significant factor.

Conclusions: While STE predicted survival outcomes in adult CA patients, RWMA did not. The decision to perform CAG after CA should include ECG under existing guidelines. The use of RWMA has limited benefits in treatment of this population.

Key Words: coronary stenosis; echocardiography; electrocardiography; heart arrest

\section{INTRODUCTION}

The most common cause of cardiac arrest (CA) is acute coronary syndrome (ACS), which accounts for $70 \%$ of all CA cases [1-3]. Coronary angiography (CAG) improves both survival and neurological outcomes in CA patients [3-5]. The current guidelines for CA patients recommend that immediate CAG be performed on patients with ST segment elevation (STE) on electrocardiography (ECG); if STE is not detected, CAG should be performed considering account instability, comorbidities, and patient characteristics [5].

\section{Original Article}

Received: September 24, 2020

Revised: November 26, 2020

Accepted: December 4, 2020

\section{Corresponding author}

Yong Soo Cho

Department of Emergency Medicine,

Chonnam National University

Hospital, 42 Jebong-ro, Dong-gu,

Gwangju 61469, Korea

Tel: +82-62-220-6809

Fax: +82-62-228-7417

E-mail: semi-moon@hanmail.net

Copyright @ 2020 The Korean Society of Critical Care Medicine

This is an Open Access article distributed under the terms of Creative Attributions Non-Commercial License (https:// creativecommons.org/li-censes/by-nc/4.0/) which permits unrestricted noncommercial use, distribution, and reproduction in any medium, provided the original work is properly cited. 
In ACS patients, ECG is helpful for prediction of patient outcomes. In several studies of ACS patients who underwent primary percutaneous coronary intervention (PCI), STE was associated with poorer survival-to-hospital discharge rates [68]. These results are similar to those in CA patients. In a previous study [9], CA patients who underwent CAG had a low incidence of survival-to hospital discharge when STE was not present because ECG detects coronary artery stenosis. The presence of coronary artery stenosis increases in-hospital mortality rates and leads to poor neurological recovery in CA patients [9]. However, the ability of ECG to predict coronary artery stenosis in CA patients is limited [3,10-12].

When diagnosing coronary artery stenosis in ACS patients, regional wall motion abnormality (RWMA) assessment using two-dimensional echocardiography (2DE) is more useful than STE assessment using ECG $[13,14]$ because RWMA assessment is more sensitive to coronary artery stenosis $[11,15]$. As in ACS, if RWMA assessment is more capable of diagnosing coronary artery stenosis in CA patients than is STE assessment, it may predict the outcomes of CA patients with greater accuracy than STE assessment using ECG. We investigated whether RWMA assessment using 2DE could predict prognosis more effectively than STE assessment using ECG in CA patients who underwent CAG after return of spontaneous circulation (ROSC).

\section{MATERIALS AND METHODS}

\section{Study Design and Patients}

This was a retrospective observational study of adult CA survivors who were treated at Chonnam National University Hospital in Kwangju, Korea, between January 2006 and December 2018. This study was approved by the Institutional Review Board of the Chonnam National University Hospital (IRB No. CNUH-2020-104); the need for informed consent was waived.

Adult (age $\geq 18$ years) CA patients with presumed cardiac etiology who underwent ECG, 2DE, and CAG immediately after ROSC were included in the study. In patients with CA, including out-of-hospital cardiac arrest (OHCA) and in-hospital cardiac arrest, cardiac etiology was defined as follows [16-18]: CA was presumed to be of cardiac etiology unless it was known or likely to have been caused by trauma, submersion, drug overdose, asphyxia, exsanguination, or any other noncardiac cause as best determined by rescuers. No patients who did not undergo CAG were enrolled in the study because they either died shortly after ROSC or their caregivers withdrew them from treatment. The exclusion criteria were as fol-

\section{KEY MESSAGES}

- Both ST segment elevation (STE) and regional wall motion abnormality (RWMA) were independent predictors of coronary artery stenosis but not of neurological outcomes.

- In our study of cardiac arrest patients, STE predicted survival, but RWMA did not.

- The use of RWMA has limited benefits in treatment of this population.

lows: (1) 2DE performed after CAG and (2) CAG performed at least 24 hours after ROSC $[5,9,10]$ (Figure 1). A total of 145 patients was enrolled.

\section{Measurements}

We extracted the following data from the electronic medical records of CA survivors: age; sex; past history; first monitored rhythm; CA etiology; OHCA; presence of a witness on collapse; bystander cardiopulmonary resuscitation (CPR); time to ROSC (time interval from recognition of collapse to ROSC); levels of serum troponin-I, brain natriuretic peptide, and lactate; ST segment change from the initial ECG; RWMA assessment using 2DE; presence of significant stenosis on CAG; and interval from emergency department (ED) presentation to CAG. Data regarding CA, including initial arrhythmia, witnessed arrest status, administration of bystander CPR, comorbidities (if any), and changes from initial ECG findings, were systematically collected upon admission according to Utsteinstyle guidelines [16-18]. The primary outcome in our study was in-hospital mortality. The secondary outcomes were

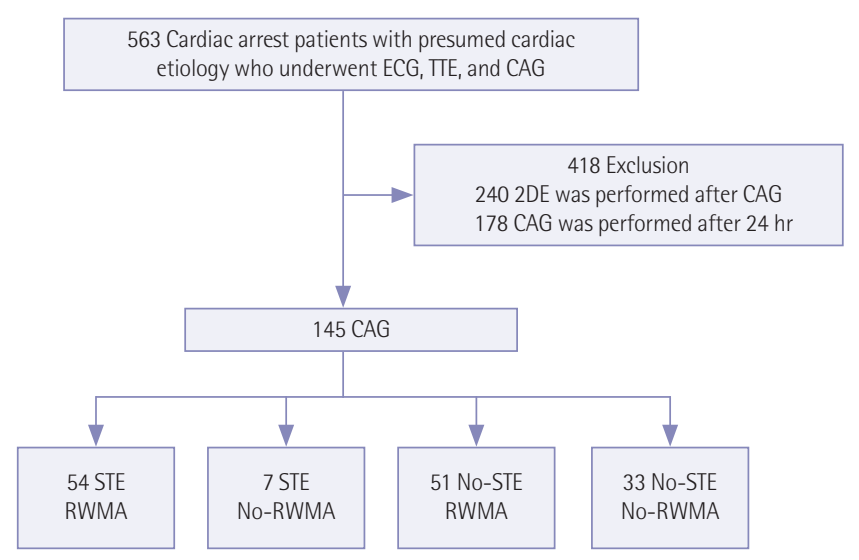

Figure 1. Flowchart of the patient selection process. ECG: electrocardiography; TTE: transthoracic echocardiography; CAG: coronary angiography; 2DE: two-dimensional echocardiogram; STE: ST elevation; RWMA: regional wall motion abnormality. 
Glasgow-Pittsburgh Cerebral Performance Category (CPC) score measured at 6 months after discharge and significant coronary artery stenosis observed on CAG.

During the study period, all patients received CPR and postCA care according to the advanced cardiac life support guidelines $[19,20]$. All patients received standard intensive care, including extracorporeal membrane oxygenation and targeted temperature management (TTM), according to institutional protocols. Throughout the study, CAG was performed at the discretion of the attending cardiologist. The timing for CAG was determined by an interventional cardiologist. The decision to perform subsequent PCI or medical treatment was based on the judgment of the attending cardiologist and the angiographic findings of the patients. Significant coronary artery stenosis was defined as stenosis $\geq 70 \%$ of one or more major epicardial coronary arteries, except the left main coronary artery, for which $\geq 50 \%$ stenosis was considered significant $[21,22]$. In patients with multivessel disease, revascularization was performed in the culprit vessel only, whereas revascularization for other significant lesions was performed in the elective phase [16].

A cardiologist performed 2DE at bedside in the ED during preparation for CAG. RWMA is defined as hypokinesis, dyskinesis, or akinesis of a segment of the left ventricle compared to the other contracting segments of the chamber [23]. RWMA included all cases of single or multiple hypokinesia, dyskinesia, or akinesia in any of the 17 myocardial segments. ECG was performed upon arrival of the patient at the ED. In the absence of left ventricular hypertrophy and bundle branch block, STE was defined as new STE at the J-point in two continuous leads with a cutoff-point $\geq 1 \mathrm{~mm}$ in all leads other than V2-V3, where the following cutoff-points were applied: $\geq 2 \mathrm{~mm}$ in males aged $\geq 40$ years; $\geq 2.5 \mathrm{~mm}$ in males aged $<40$ years; and $\geq 1.5 \mathrm{~mm}$ in females regardless of age [24].

At 6 months after discharge, neurological outcomes were assessed using the Glasgow-Pittsburgh CPC scale and recorded as CPC 1 (good performance), CPC 2 (moderate disability), CPC 3 (severe disability), CPC 4 (vegetative state), or CPC 5 (brain death or death). We defined a good neurological outcome as a CPC score of 1 or 2 and a poor neurological outcome as a CPC score of 3-5 [25].

\section{Statistical Analysis}

Continuous variables were expressed as mean and standard deviation or median and interquartile range based on normality. The Mann-Whitney U-test and independent t-tests were conducted for comparison of continuous variables, as appropriate. Categorical variables were presented as frequency and percentage. Comparisons of categorical variables were performed using the chi-square or Fisher exact test, as appropriate. Multivariable logistic regression analysis was performed to adjust for potential confounders determined by univariable analysis. All variables with P-value $<0.2$ in the univariable analysis were included in the multivariable regression analysis. Variables that were significant in multivariable analysis were adjusted for 2DE and RWMA. Odds ratio (OR) with 95\% confidence interval (CI) were calculated for survival, good neurological outcome, and coronary artery stenosis. Data were analyzed using R software version 4.0.0 (R Foundation for Statistical Computing, Vienna, Austria). A twosided significance level of 0.05 was used to determine statistical significance.

\section{RESULTS}

Among 145 patients, in-hospital death was observed in 36 (24.8\%) (Figure 1), good neurological outcome was observed in 78 (53.8\%), and significant stenosis of the coronary artery was observed in 76 (52.4\%). The flowchart is shown in Figure 1. In all patients, ECG was performed immediately after the visit, 2DE was performed at 151 minutes (interquartile range, 5 minutes-589 minutes), and CAG was performed at $318 \mathrm{~min}$ utes (interquartile range, 151 minutes-789 minutes). During 2DE, 105 patients $(72.4 \%)$ had RWMA. On ECG, 61 patients (42.1\%) had STE (Table 1). The incidence of STE differed significantly between the survival and death groups $(\mathrm{P}=0.037)$, while RWMA incidence showed no difference between groups $(\mathrm{P}=0.853)$. In terms of good neurological outcomes, no difference was observed between RWMA and STE $(\mathrm{P}=0.995, \mathrm{P}=$ 0.817). The incidence of significant coronary artery stenosis was significantly different between the RWMA and STE groups ( $\mathrm{P}<0.001, \mathrm{P}=0.004)$. Other variables related to prognosis of CA patients, such as age, sex, medical history, presence of a witness, CPR administration by a bystander, initial shockable rhythm, and total arrest time, did not differ between the STE and RWMA groups (Table 1).

In univariable analysis of survival, total arrest time, hypertension, OHCA, troponin-I, NT-proB-type natriuretic peptide, and STE had P-values $<0.2$, and a multivariable analysis using these variables revealed that only total arrest time $(\mathrm{P}=0.011)$ and STE $(\mathrm{P}=0.035)$ were significant. The OR and 95\% CI obtained after adjusting for significant variables in the multivariable analysis of survival outcomes were only significant for STE (OR, 0.40; 95\% CI, 0.17-0.94) (Table 2). In the multivari- 


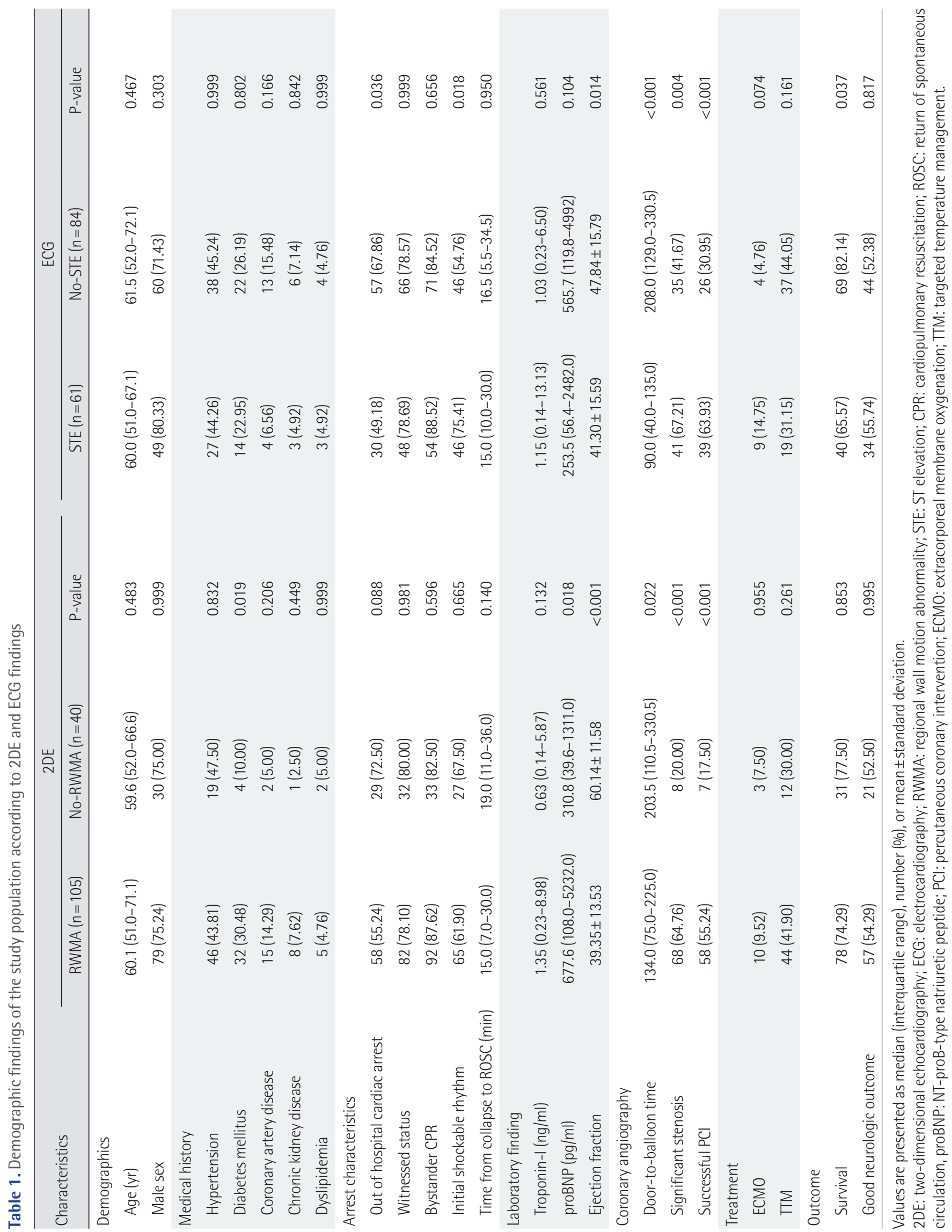


Kim DK, et al. STE or RWMA for predicting outcomes after CA

Table 2. Logistic regression analysis for survival outcomes

\begin{tabular}{|c|c|c|c|c|}
\hline \multirow{2}{*}{ Parameter } & \multicolumn{2}{|c|}{ Univariable } & \multicolumn{2}{|c|}{ Multivariable } \\
\hline & OR (95\% Cl) & P-value & $\mathrm{OR}(95 \% \mathrm{Cl})$ & P-value \\
\hline Hypertension & $1.89(0.86-4.16)$ & 0.113 & $1.93(0.82-4.52)$ & 0.130 \\
\hline Out of hospital cardiac arrest & $1.73(0.81-3.69)$ & 0.160 & $1.75(0.66-4.68)$ & 0.264 \\
\hline Time from collapse to ROSC & $0.98(0.96-1.00)$ & 0.048 & $0.97(0.95-0.99)$ & 0.011 \\
\hline Troponin-I & $0.99(0.98-1.00)$ & 0.131 & $1.00(0.98-1.01)$ & 0.407 \\
\hline proBNP & $1.00(1.00-1.00)$ & 0.071 & $1.00(1.00-1.00)$ & 0.076 \\
\hline ECG (ST elevation) & $0.41(0.19-0.89)$ & 0.025 & $0.40(0.17-0.94)$ & 0.035 \\
\hline 2DE (RWMA) & $0.84(0.35-1.99)$ & 0.689 & NA & NA \\
\hline
\end{tabular}

OR: odds ratio; Cl: confidence interval; ROSC: return of spontaneous circulation; proBNP: NT-proB-type natriuretic peptide; ECG: electrocardiography; 2DE: two-dimensional echocardiogram; RWMA: regional wall motion abnormality; NA: not applicable.

Table 3. Logistic regression analysis for good neurological outcomes

\begin{tabular}{|c|c|c|c|c|}
\hline \multirow{2}{*}{ Parameter } & \multicolumn{2}{|c|}{ Univariable } & \multicolumn{2}{|c|}{ Multivariable } \\
\hline & OR (95\% Cl) & P-value & OR $(95 \% \mathrm{Cl})$ & P-value \\
\hline Sex & 3.07 (1.39-6.78) & 0.006 & $3.44(1.29-9.17)$ & 0.013 \\
\hline Chronic kidney disease & $0.10(0.01-0.79)$ & 0.029 & $0.13(0.01-1.34)$ & 0.087 \\
\hline Dyslipidemia & $5.50(0.65-46.86)$ & 0.119 & $5.85(0.42-82.22)$ & 0.190 \\
\hline Witnessed status & $2.18(0.97-4.91)$ & 0.061 & $1.11(0.40-3.09)$ & 0.834 \\
\hline Bystander CPR & $3.17(1.14-8.79)$ & 0.027 & $0.66(0.18-2.44)$ & 0.536 \\
\hline Initial shockable rhythm & $3.01(1.49-6.10)$ & 0.002 & $4.46(1.84-10.79)$ & $<0.001$ \\
\hline Time from collapse to ROSC & $0.95(0.92-0.97)$ & $<0.001$ & $0.93(0.91-0.96)$ & $<0.001$ \\
\hline ECG (ST elevation) & $1.14(0.59-2.22)$ & 0.689 & NA & NA \\
\hline 2DE (RWMA) & $1.07(0.52-2.23)$ & 0.847 & NA & NA \\
\hline
\end{tabular}

OR: odds ratio; $\mathrm{Cl}$ : confidence interval; CPR: cardiopulmonary resuscitation; ROSC: return of spontaneous circulation; ECG: electrocardiography; 2DE: two-dimensional echocardiogram; RWMA: regional wall motion abnormality; NA: not applicable.

Table 4. Logistic regression analysis for coronary artery stenosis

\begin{tabular}{|c|c|c|c|c|}
\hline \multirow{2}{*}{ Parameter } & \multicolumn{2}{|c|}{ Univariable } & \multicolumn{2}{|c|}{ Multivariable } \\
\hline & OR $(95 \% \mathrm{Cl})$ & P-value & OR $(95 \% \mathrm{Cl})$ & P-value \\
\hline Age & $1.02(1.00-1.05)$ & 0.052 & $1.04(1.01-1.07)$ & 0.021 \\
\hline Sex & $1.78(0.83-3.82)$ & 0.139 & $2.56(1.02-6.45)$ & 0.045 \\
\hline Hypertension & $1.56(0.80-3.01)$ & 0.190 & $1.55(0.71-3.39)$ & 0.269 \\
\hline Troponin-I & $1.02(1.00-1.04)$ & 0.094 & 1.02 (0.99-1.04) & 0.182 \\
\hline ECG (ST elevation) & $2.87(1.44-5.71)$ & 0.003 & $1.88(0.86-4.12)$ & 0.116 \\
\hline 2DE (RWMA) & 7.35 (3.07-17.58) & $<0.001$ & $6.07(2.37-15.54)$ & $<0.001$ \\
\hline
\end{tabular}

OR: odds ratio; Cl: confidence interval; ECG: electrocardiography; 2DE: two-dimensional echocardiogram; RWMA: regional wall motion abnormality.

able analysis of good neurological outcomes, only sex $(\mathrm{P}=0.013)$, initial shockable rhythm $(\mathrm{P}<0.001)$, and total arrest time $(\mathrm{P}<0.001)$ were significant (Table 3$)$. Neither STE nor RWMA was a significant predictor of good neurological outcomes. In the multivariable analysis of stenosis, age $(\mathrm{P}=0.021)$, sex $(\mathrm{P}=0.045)$, and RWMA $(\mathrm{P}<0.001)$ were signifi- cant. The OR and 95\% CI for stenosis were significant for RWMA (OR, 6.07; 95\% CI, 2.37-15.54) (Table 4). The demographic findings of RWMA and no-RWMA in 84 no-STE patients are shown in Supplementary Table 1. In the multivariable analysis, RWMA was only significant for stenosis (OR, $6.01 ; 95 \%$ CI, 1.78-20.21), and there were no significant differ- 
ences in survival and neurologic outcomes between the two groups (Supplementary Table 2).

\section{DISCUSSION}

STE was independently associated with survival outcomes, whereas RWMA was not. Both STE and RWMA were independent predictors of coronary artery stenosis but not of neurological outcomes.

In the multivariable analysis, total arrest time and STE were significant predictors of survival outcomes. After adjusting for total arrest time, the OR for STE was 0.37 (95\% CI, 0.17-0.83). In a previous study [9] of patients with CA, the survival-tohospital discharge rate was $55.1 \%$ (109/198) for all patients with STE, higher than the rate of $41.3 \%(226 / 547)$ in patients without STE (adjusted $\mathrm{P}=0.007$ ). However, in patients who underwent CAG, the survival-to-hospital discharge rate was $55.7 \%(107 / 192)$ when STE was found and 66.8\% (165/247) when it was not (adjusted $\mathrm{P}=0.01$ ). We studied patients who underwent CAG, and survival was poor when STE was present, consistent with the findings of the previous study [9]. This is likely due to the association of coronary artery stenosis with mortality in CA patients.

In the multivariable analysis of significant coronary artery stenosis, only RWMA and STE were significant. RWMA had a higher OR than STE; however, this did not lead to improved survival. Several studies have shown that it is PCI, not CAG that reduces mortality in CA patients $[3,9,11,26,27]$. Therefore, CAG is only recommended after CA in patients with significant coronary artery stenosis. However, it is not easy to predict stenosis before CAG $[1,10-12,28]$ because the clinical signs for ischemia caused by significant stenosis are unclear, and the available diagnostic tools are of limited use [1,10-12]. ECG, the most widely-used tool, is a poor predictor of significant stenosis in CA patients [3,10-12]. Significant stenosis was not observed in $20 \%$ of STE patients, while it was observed in $25 \%$ of patients without STE. This finding suggests the need for further research using other diagnostic tools $[3,29]$. We assessed the presence of RWMA on 2DE, which is superior to ECG for diagnosis of significant coronary artery stenosis in ACS patients. However, in our study of CA patients, the presence of RWMA did not predict patient survival. This suggests that the characteristics of RWMA differ between CA and ACS.

In the present study, RWMA was observed in 105 patients, whereas STE was observed in 61 patients. This suggests that RWMA can detect stenosis unrelated to survival. In addition, the accuracy of RWMA assessment can decrease due to the presence of Takotsubo syndrome [30], which can occur after CA and is difficult to distinguish from RWMA on 2DE. Postresuscitation myocardial dysfunction (PRMD) occurring after CA can further reduce the accuracy of RWMA assessment. PRMD is reversible myocardial dysfunction caused by global ischemia that occurs during $\mathrm{CA}$, and global myocardial dysfunction is the most common pattern [31,32]. PRMD might have influenced the results of this study and can hinder the ability of physicians to identify RWMA.

In general, cardiac enzymes, such as troponin, predict coronary stenosis and patient outcomes. However, troponin did not show any significant relationships in our study. This observation is consistent with previous reports demonstrating that troponin has a high rate of false negative results $(2.5 \%$ $7.8 \%$ ) and is not useful in patients with CA, in contrast with patients with ACS [11]. The treatment strategy for patients with ROSC after CA typically involves CAG and TTM [5]. TTM results in better prognosis when initiated shortly after ROSC, but the optimal timing of CAG, especially in non-ST-elevation myocardial infarction (NSTEMI) patients, remains controversial $[2,3,19]$. In recent studies of NSTEMI, performing CAG shortly after CA did not show any clear benefit in terms of prognostic measures such as 30-day mortality [2,3,19,29]. In CA patients, CAG also has disadvantages, such as hemodynamic instability, exposure to contrast, and delays in appropriate diagnosis of other possible causes of CA, which can result in incorrect therapeutic decisions $[19,29]$.

We hypothesized that RWMA assessment would help determine whether early CAG should be performed in patients without STE but found that RWMA was a useful predictor of significant coronary artery stenosis rather than of survival outcomes. Therefore, the benefits of 2DE in CA patients were limited. We chose to include only patients who had undergone 2DE prior to CAG. In patients who underwent 2DE after CAG, RWMA findings could differ due to successful PCI. However, we aimed to avoid preconceptions regarding interpretation of RWMA by the cardiologist, a potential consequence of knowing CAG results in advance.

The present study has several limitations. STE was defined according to the Fourth Universal Definition of Myocardial Infarction, so ECG results such as left main or post infarction were classified as no-STE. However, some clinicians have different opinions about these classifications. In our hospital, ECG is performed immediately after arrival at the ED. If STE is observed, CAG is performed as quickly as possible; if there is no STE, the decision to perform CAG is based on patient instability, comorbidities, and characteristics. In the ED, 2DE is 
performed at bedside during CAG preparation. In our study, STE patients only underwent 2DE if it did not interfere with CAG initiation; thus, selection bias could have been introduced. Since bias is greater in STE, we conducted further analyses of patients with no-STE in an attempt to reduce the impact of this limitation. In addition, since we only targeted patients who underwent $\mathrm{CAG}$, it is possible that patients were selected under the presumption that CAG would be advantageous to their respective prognoses. Our study was limited by the different timings of 2DE and CAG execution. In the future, multicenter trials that address the timing of various procedures in CA patients, such as optimal timing of 2DE implementation, should be conducted.

In conclusion, both RWMA and STE are helpful for prediction of significant coronary artery stenosis. However, while STE predicted survival, RWMA did not. The decision to perform CAG after CA should include ECG results under the existing guidelines. The use of RWMA has limited benefits in treatment of this population.

\section{CONFLICT OF INTEREST}

No potential conflict of interest relevant to this article was reported.

\section{ACKNOWLEDGMENTS}

This study was supported by a grant (CRI 18008-1) from the Chonnam National University Hospital Biomedical Research Institute.

\section{ORCID}

$\begin{array}{ll}\text { Dong Ki Kim } & \text { https://orcid.org/0000-0003-4069-1902 } \\ \text { Yong Soo Cho } & \text { https://orcid.org/0000-0001-8306-2298 } \\ \text { Joochan Kim } & \text { https://orcid.org/0000-0002-1768-0642 } \\ \text { Byung Kook Lee } & \text { https://orcid.org/0000-0003-3571-9448 } \\ \text { Dong Hun Lee } & \text { https://orcid.org/0000-0003-3612-3443 } \\ \text { Eujene Jung } & \text { https://orcid.org/0000-0003-3802-5636 } \\ \text { Jeong Mi Moon } & \text { https://orcid.org/0000-0002-9182-5475 } \\ \text { Byeong Jo Chun } & \text { https://orcid.org/0000-0002-5240-4213 }\end{array}$

\section{AUTHOR CONTRIBUTIONS}

Conceptualization: YSC. Data curation: DKK, JK, YSC, DHL. Formal analysis: YSC, JMM. Methodology: JK, YSC. Project administration: DKK, JK, BJC. Visualization: YSC, JMM, BJC.
Writing-original draft: DKK, JK, BKL. Writing-review \& editing: BKL, DHL, YSC.

\section{SUPPLEMENTARY MATERIALS}

Supplementary materials can be found via https://doi.org/ 10.4266/acc.2020.00773.

\section{REFERENCES}

1. Spaulding CM, Joly LM, Rosenberg A, Monchi M, Weber SN, Dhainaut JF, et al. Immediate coronary angiography in survivors of out-of-hospital cardiac arrest. N Engl J Med 1997;336: 1629-33.

2. Lemkes JS, Janssens GN, van der Hoeven NW, Jewbali LS, Dubois EA, Meuwissen M, et al. Coronary angiography after cardiac arrest without ST-segment elevation. N Engl J Med 2019;380:1397-407.

3. Jentzer JC, Scutella M, Pike F, Fitzgibbon J, Krehel NM, Kowalski L, et al. Early coronary angiography and percutaneous coronary intervention are associated with improved outcomes after out of hospital cardiac arrest. Resuscitation 2018;123:15-21.

4. Reynolds JC, Callaway CW, El Khoudary SR, Moore CG, Alvarez RJ, Rittenberger JC. Coronary angiography predicts improved outcome following cardiac arrest: propensity-adjusted analysis. J Intensive Care Med 2009;24:179-86.

5. Callaway CW, Donnino MW, Fink EL, Geocadin RG, Golan E, Kern KB, et al. Part 8: Post-Cardiac Arrest Care: 2015 American Heart Association Guidelines Update for Cardiopulmonary Resuscitation and Emergency Cardiovascular Care. Circulation 2015;132(18 Suppl 2):S465-82.

6. Cannon CP, Weintraub WS, Demopoulos LA, Vicari R, Frey MJ, Lakkis N, et al. Comparison of early invasive and conservative strategies in patients with unstable coronary syndromes treated with the glycoprotein IIb/IIIa inhibitor tirofiban. N Engl J Med 2001;344:1879-87.

7. Stone GW, Grines CL, Cox DA, Garcia E, Tcheng JE, Griffin JJ, et al. Comparison of angioplasty with stenting, with or without abciximab, in acute myocardial infarction. N Engl J Med 2002;346:957-66.

8. Roe MT, Messenger JC, Weintraub WS, Cannon CP, Fonarow GC, Dai D, et al. Treatments, trends, and outcomes of acute myocardial infarction and percutaneous coronary intervention. J Am Coll Cardiol 2010;56:254-63.

9. Kern KB, Lotun K, Patel N, Mooney MR, Hollenbeck RD, McPherson JA, et al. Outcomes of comatose cardiac arrest survivors with and without ST-segment elevation myocardial 
infarction: importance of coronary angiography. JACC Cardiovasc Interv 2015;8:1031-40.

10. Dumas F, Cariou A, Manzo-Silberman S, Grimaldi D, Vivien $\mathrm{B}$, Rosencher J, et al. Immediate percutaneous coronary intervention is associated with better survival after out-of-hospital cardiac arrest: insights from the PROCAT (Parisian Region Out of hospital Cardiac ArresT) registry. Circ Cardiovasc Interv 2010;3:200-7.

11. Dumas F, Bougouin W, Geri G, Lamhaut L, Rosencher J, Pène F, et al. Emergency percutaneous coronary intervention in post-cardiac arrest patients without ST-segment elevation pattern: insights from the PROCAT II registry. JACC Cardiovasc Interv 2016;9:1011-8.

12. Aurore A, Jabre P, Liot P, Margenet A, Lecarpentier E, Combes $\mathrm{X}$. Predictive factors for positive coronary angiography in outof-hospital cardiac arrest patients. Eur J Emerg Med 2011;18: 73-6.

13. Sabia P, Afrookteh A, Touchstone DA, Keller MW, Esquivel L, Kaul S. Value of regional wall motion abnormality in the emergency room diagnosis of acute myocardial infarction: a prospective study using two-dimensional echocardiography. Circulation 1991;84(3 Suppl):I85-92.

14. Horowitz RS, Morganroth J, Parrotto C, Chen CC, Soffer J, Pauletto FJ. Immediate diagnosis of acute myocardial infarction by two-dimensional echocardiography. Circulation 1982; 65:323-9.

15. American College of Cardiology Foundation Appropriate Use Criteria Task Force; American Society of Echocardiography; American Heart Association; American Society of Nuclear Cardiology; Heart Failure Society of America; Heart Rhythm Society, et al. ACCF/ASE/AHA/ASNC/HFSA/HRS/SCAI/ SCCM/SCCT/SCMR 2011 Appropriate Use Criteria for Echocardiography. A Report of the American College of Cardiology Foundation Appropriate Use Criteria Task Force, American Society of Echocardiography, American Heart Association, American Society of Nuclear Cardiology, Heart Failure Society of America, Heart Rhythm Society, Society for Cardiovascular Angiography and Interventions, Society of Critical Care Medicine, Society of Cardiovascular Computed Tomography, and Society for Cardiovascular Magnetic Resonance Endorsed by the American College of Chest Physicians. J Am Coll Cardiol 2011;57:1126-66.

16. Bro-Jeppesen J, Kjaergaard J, Wanscher M, Pedersen F, Holmvang L, Lippert FK, et al. Emergency coronary angiography in comatose cardiac arrest patients: do real-life experiences support the guidelines? Eur Heart J Acute Cardiovasc Care 2012;1:291-301.
17. Langhelle A, Nolan J, Herlitz J, Castren M, Wenzel V, Soreide E, et al. Recommended guidelines for reviewing, reporting, and conducting research on post-resuscitation care: the Utstein style. Resuscitation 2005;66:271-83.

18. Jacobs I, Nadkarni V, Bahr J, Berg RA, Billi JE, Bossaert L, et al. Cardiac arrest and cardiopulmonary resuscitation outcome reports: update and simplification of the Utstein templates for resuscitation registries: a statement for healthcare professionals from a task force of the International Liaison Committee on Resuscitation (American Heart Association, European Resuscitation Council, Australian Resuscitation Council, New Zealand Resuscitation Council, Heart and Stroke Foundation of Canada, InterAmerican Heart Foundation, Resuscitation Councils of Southern Africa). Circulation 2004;110:3385-97.

19. Kim YJ, Kim YH, Lee BK, Park YS, Sim MS, Kim SJ, et al. Immediate versus early coronary angiography with targeted temperature management in out-of-hospital cardiac arrest survivors without ST-segment elevation: a propensity scorematched analysis from a multicenter registry. Resuscitation 2019;135:30-6.

20. Ryoo SM, Jeon SB, Sohn CH, Ahn S, Han C, Lee BK, et al. Predicting outcome with diffusion-weighted imaging in cardiac arrest patients receiving hypothermia therapy: multicenter retrospective cohort study. Crit Care Med 2015;43:2370-7.

21. Neglia D, Rovai D, Caselli C, Pietila M, Teresinska A, AguadéBruix S, et al. Detection of significant coronary artery disease by noninvasive anatomical and functional imaging. Circ Cardiovasc Imaging 2015;8:e002179.

22. Maddox TM, Stanislawski MA, Grunwald GK, Bradley SM, Ho PM, Tsai TT, et al. Nonobstructive coronary artery disease and risk of myocardial infarction. JAMA 2014;312:1754-63.

23. Cerqueira MD, Weissman NJ, Dilsizian V, Jacobs AK, Kaul S, Laskey WK, et al. A statement for healthcare professionals from the Cardiac Imaging Committee of the Council on Clinical Cardiology of the American Heart Association. Circulation 2002;105:539-42.

24. Thygesen K, Alpert JS, Jaffe AS, Chaitman BR, Bax JJ, Morrow DA, et al. Fourth Universal Definition of Myocardial Infarction (2018). J Am Coll Cardiol 2018;72:2231-64.

25. Booth CM, Boone RH, Tomlinson G, Detsky AS. Is this patient dead, vegetative, or severely neurologically impaired? Assessing outcome for comatose survivors of cardiac arrest. JAMA 2004;291:870-9.

26. Cronier P, Vignon P, Bouferrache K, Aegerter P, Charron C, Templier F, et al. Impact of routine percutaneous coronary intervention after out-of-hospital cardiac arrest due to ventricular fibrillation. Crit Care 2011;15:R122. 
27. Noc M, Fajadet J, Lassen JF, Kala P, MacCarthy P, Olivecrona $\mathrm{GK}$, et al. Invasive coronary treatment strategies for out-ofhospital cardiac arrest: a consensus statement from the European association for percutaneous cardiovascular interventions (EAPCI)/stent for life (SFL) groups. EuroIntervention 2014;10:31-7.

28. Millin MG, Comer AC, Nable JV, Johnston PV, Lawner BJ, Woltman N, et al. Patients without ST elevation after return of spontaneous circulation may benefit from emergent percutaneous intervention: a systematic review and meta-analysis. Resuscitation 2016;108:54-60.

29. Wester A, Mohammad MA, Andell P, Rylance R, Dankiewicz J, Friberg $\mathrm{H}$, et al. Coronary angiographic findings and outcomes in patients with sudden cardiac arrest without ST-ele- vation myocardial infarction: a SWEDEHEART study. Resuscitation 2018;126:172-8.

30. Ghadri JR, Wittstein IS, Prasad A, Sharkey S, Dote K, Akashi YJ, et al. International Expert Consensus Document on Takotsubo Syndrome (Part II): Diagnostic Workup, Outcome, and Management. Eur Heart J 2018;39:2047-62.

31. Chang WT, Ma MH, Chien KL, Huang CH, Tsai MS, Shih FY, et al. Postresuscitation myocardial dysfunction: correlated factors and prognostic implications. Intensive Care Med 2007; 33:88-95.

32. Cha KC, Kim HI, Kim OH, Cha YS, Kim H, Lee KH, et al. Echocardiographic patterns of postresuscitation myocardial dysfunction. Resuscitation 2018;124:90-5. 
Supplementary Table 1. Demographic findings of the no-STE patients

\begin{tabular}{|c|c|c|c|}
\hline \multirow{2}{*}{ Characteristics } & \multicolumn{3}{|c|}{$2 \mathrm{DE}$} \\
\hline & RWMA $(n=105)$ & No-RWMA $(n=40)$ & P-value \\
\hline \multicolumn{4}{|l|}{ Demographics } \\
\hline Age (yr) & $63.09(53.58-74.04)$ & $58.09(52.03-65.02)$ & 0.243 \\
\hline Male sex & $36(70.59)$ & $24(72.73)$ & 0.999 \\
\hline \multicolumn{4}{|l|}{ Medical history } \\
\hline Hypertension & $23(45.10)$ & $15(45.45)$ & 0.999 \\
\hline Diabetes mellitus & $19(37.25)$ & $3(9.09)$ & 0.009 \\
\hline Coronary artery disease & $11(21.57)$ & $2(6.06)$ & 0.107 \\
\hline Chronic kidney disease & $6(11.76)$ & 0 & 0.107 \\
\hline Dyslipidemia & $2(3.92)$ & $2(6.06)$ & 0.999 \\
\hline \multicolumn{4}{|l|}{ Arrest characteristics } \\
\hline Out of hospital cardiac arrest & $33(64.71)$ & $24(72.73)$ & 0.596 \\
\hline Witnessed status & $40(78.43)$ & $26(78.79)$ & 0.999 \\
\hline Bystander CPR & $43(84.31)$ & $28(84.85)$ & 0.999 \\
\hline Initial shockable rhythm & $23(45.10)$ & $23(69.70)$ & 0.047 \\
\hline Time from collapse to ROSC (min) & $15.00(5.00-30.00)$ & $20.00(12.00-40.00)$ & 0.154 \\
\hline \multicolumn{4}{|l|}{ Laboratory finding } \\
\hline $\operatorname{Tnl}$ & $1.13(0.29-6.50)$ & $0.85(0.18-6.34)$ & 0.614 \\
\hline BNP & $2,019(250.9-7,612)$ & $310.8(71.46-1330)$ & 0.002 \\
\hline $\mathrm{EF}$ & $39.37 \pm 12.36$ & $60.92 \pm 10.81$ & $<0.001$ \\
\hline \multicolumn{4}{|l|}{ CAG } \\
\hline Door-to-balloon time & $185.0(132.0-315.0)$ & $225.0(123.0-336.0)$ & 0.735 \\
\hline Significant stenosis & $29(56.86)$ & $6(18.18)$ & 0.001 \\
\hline Successful PCl & $21(41.18)$ & $5(15.15)$ & 0.023 \\
\hline \multicolumn{4}{|l|}{ Treatment } \\
\hline ECMO & $3(5.88)$ & 1 (3.03) & 0.940 \\
\hline ПТ & $27(52.94)$ & $10(30.30)$ & 0.069 \\
\hline \multicolumn{4}{|l|}{ Outcome } \\
\hline Survival & $42(82.35)$ & 27 (81.82) & 0.999 \\
\hline Good neurologic outcome & $26(50.98)$ & $18(54.55)$ & 0.924 \\
\hline
\end{tabular}

Values are presented as median (interquartile range), number (\%), or mean \pm standard deviation.

STE: ST elevation; 2DE: two-dimensional echocardiography; RWMA: regional wall motion abnormality; CPR: cardiopulmonary resuscitation; ROSC: return of spontaneous circulation; Tnl: troponin I; BNP: B-type natriuretic peptide; EF: ejection fraction; CAG: coronary angiography; PCl: percutaneous coronary intervention; ECMO: extracorporeal membrane oxygenation; TM: targeted temperature management. 
Kim DK, et al. STE or RWMA for predicting outcomes after CA

Supplementary Table 2. Multivariable logistic regression analysis for each outcome of no-STE patients

\begin{tabular}{|c|c|c|c|c|c|c|}
\hline \multirow{2}{*}{ Parameter } & \multicolumn{2}{|c|}{ Survival } & \multicolumn{2}{|c|}{$\mathrm{CPC}$} & \multicolumn{2}{|c|}{ Stenosis } \\
\hline & OR (95\% Cl) & P-value & OR (95\% Cl) & P-value & OR (95\% Cl) & P-value \\
\hline Age & $0.95(0.90-1.00)$ & 0.044 & NA & NA & $1.06(1.01-1.11)$ & 0.016 \\
\hline Sex & NA & NA & $\mathrm{N} / \mathrm{A}$ & NA & $3.88(1.05-14.31)$ & 0.042 \\
\hline Chronic kidney disease & $0.09(0.01-0.73)$ & 0.024 & N/A & NA & NA & NA \\
\hline Time from collapse to ROSC & NA & NA & $0.92(0.88-0.96)$ & $<0.001$ & NA & NA \\
\hline 2DE (RWMA) & NA & NA & $\mathrm{N} / \mathrm{A}$ & NA & $6.01(1.78-20.21)$ & 0.004 \\
\hline
\end{tabular}

STE: ST elevation; CPC: cerebral performance category; OR: odds ratio; Cl: confidence interval; ROSC: return of spontaneous circulation; 2DE: two-dimensional echocardiogram; RWMA: regional wall motion abnormality. 